University of Nebraska - Lincoln

DigitalCommons@University of Nebraska - Lincoln

Valery Forbes Publications

Papers in the Biological Sciences

2010

Improving the Value of Standard Toxicity Test Data in REACH

Magnus Breitholtz

Stockholm University, magnus.breitholtz@itm.su.se

Elin Lundström

Stockholm University, elin.lundstrom@itm.su.se

Ulrika Dahl

Stockholm University, ulrika.dahl@itm.su.se

Valery E. Forbes

University of Nebraska-Lincoln, veforbes@umn.edu

Follow this and additional works at: https://digitalcommons.unl.edu/biosciforbes

Part of the Pharmacology, Toxicology and Environmental Health Commons

Breitholtz, Magnus; Lundström, Elin; Dahl, Ulrika; and Forbes, Valery E., "Improving the Value of Standard Toxicity Test Data in REACH" (2010). Valery Forbes Publications. 9.

https://digitalcommons.unl.edu/biosciforbes/9

This Article is brought to you for free and open access by the Papers in the Biological Sciences at DigitalCommons@University of Nebraska - Lincoln. It has been accepted for inclusion in Valery Forbes Publications by an authorized administrator of DigitalCommons@University of Nebraska - Lincoln. 
Published (as Chapter 6) in J. Eriksson et al. (eds.), Regulating Chemical Risks:

European and Global Challenges, pp. 85-98; doi: 10.1007/978-90-481-9428-5_6

Copyright (c) 2010 Springer Science+Business Media B.V. Used by permission.

\title{
Improving the Value of Standard Toxicity Test Data in REACH
}

\author{
Magnus Breitholtz, Elin Lundström, Ulrika Dahl \\ Department of Applied Environmental Science, \\ Stockholm University, SE 106 81, Stockholm, Sweden \\ email: magnus.breitholtz@itm.su.se \\ elin.lundstrom@itm.su.se \\ ulrika.dahl@itm.su.se \\ Valery Forbes \\ Department of Environmental, Social and Spatial Change, \\ Roskilde University, Roskilde, Denmark \\ Current address: University of Nebraska-Lincoln, \\ Lincoln, Nebraska, USA; email vforbes2@unl.edu
}

\begin{abstract}
Worldwide, environmental risk assessment strategies are based on the assumption that measuring direct effects of single substances, using a few single species tests, in combination with safety factors correcting for extrapolation inconsistencies, can be used to protect higher levels of biological organization, such as populations and even ecosystems. At the same time, we are currently facing a range of pollution problems (Millennium Ecosystem Assessment Series 2005), of which some could at least indirectly be linked to the fact that this assumption may not be fully valid. Consequently, there is an ongoing scientific debate on whether current chemical control protocols are sufficient for protection of ecosystems, and numerous suggestions for improvements have been presented by the scientific community, e.g. alternative tests and testing strategies. On the other hand, few of these suggestions actually reach the regulatory world (or become implemented), and risk assessment today basically follows the same paradigm as 30 years ago. While the new $\mathrm{REACH}$ regime is exceptionally ambitious, this chapter observes several problems and gaps in this regulatory framework. We suggest measures and approaches which imply increased ecological realism and understanding in future regulatory work.
\end{abstract}

Keywords: environment, REACH, risk, standardization, toxicity test 


\section{Introduction}

On the 1st of June 2007, a new European chemicals regulation came into force (REGULATION (EC) No 1907/2006). REACH (Regulation, Evaluation, Authorization and registration of CHemicals), as the legislation is called, will be introduced in a stepwise process and fully implemented in 2018. The main aims of the regulation are exceptionally ambitious in the sense that REACH "should ensure a high level of protection of human health and the environment as well as the free movement of substances, on their own, in preparations and in articles, while enhancing competitiveness and innovation. This Regulation should also promote the development of alternative methods for the assessment of hazards of substances." Knowledge about potential risks of both old (i.e. introduced on the market before 1981) and new chemical substances (introduced on the market after 1981) should be increased, and if the producer cannot produce data on the substance it will not go on the market, i.e. producers will be required to generate their own risk assessment reports. However, the legislation only covers chemical substances produced above 1 ton $(t)$ per producer and year on the European market. This means that a large number of chemicals will not be covered by the regulation, and for low-volume chemicals (produced between 1-10 t per producer and year) data will not be sufficient even for an initial characterization of inherent properties (Rudén and Hansson 2006). Currently, we have knowledge about human health and environmental risk for about 1,500 of the 30,000 chemical substances that eventually will be covered by REACH (Swedish Chemicals Inspectorate 2007). This means that within the next 10 years a great number of (eco) toxicological tests must be performed in Europe. Still, REACH assumes that ecosystems can be protected by measuring direct effects in simple toxicity tests, whereas more complex (indirect) effects may be equally important to consider (e.g. Fleeger et al. 2003). For example, up to a production volume of $100 \mathrm{t}$ per producer and year, only acute toxicity tests with a micro alga, Daphnia, a micro-organism and a fish species will be required. In fact, REACH will generate fewer systematic data as compared to the so-called new substances in the former European chemicals legislation. On the other hand, for old substances, REACH will increase the data requirements since these substances up until now have been excluded from control, unless they have been identified as priority substances. In all, REACH is an important, albeit small, step towards ensuring sustainable use of chemicals in Europe.

It is clear that the main focus in developing REACH has been related to at what level (i.e. production volume) requirements for certain relatively simple standard tests will come into force for hazard identification and dose-response assessment of single chemical substances. Little or no effort has been focused on the actual relevance of the ecotoxicological tests that should provide data for these crucial regulatory processes. As mentioned above, it has traditionally been a slow process for scientists to influence the regulatory framework, although thousands of scientific papers have presented additional test methods (e.g. reproduction tests, tests for endocrine disruption, molecular and biochemical analyses, population genetics, etc.) to improve our ability to protect ecosystems.

It is generally required that standard test methods be used for generation of toxicity data in European risk assessment (European Commission 2003; within 
Europe it has been decided that risk assessment procedures should make use primarily of the OECD test guideline program [personal communication with Yvonne Andersson, Swedish Chemicals Inspectorate]), and it is likely that the costly and elaborate process related to development of new standards has constrained the incorporation of new test methods. Although a range of factors may hamper a straightforward standardization process, we believe that the following three aspects have hindered the development of new standard methods more than others, and therefore should be highlighted: (1) lack of funding for development and inter-calibration activities, (2) standardization work has low status within academia, and (3) (too) slow process (a new standard may take up to 1015 years to develop).

The lack of funding (1) is mainly related to the fact that standardization bodies, such as ISO and OECD, do not provide central funding to support promising scientific proposals, meaning that Member States have to provide funding for these activities. Indirectly, this also means that the standardization process may be biased; larger more wealthy nations are more likely to be able to finance test development. The low status that standardization work has within academia (2) reflects the fact that it is difficult to publish such work in international peer-reviewed journals as original research. The slowness of the standardization process (3) likely depends on both of the first two reasons (1 and 2) but also on the inherently bureaucratic process, in which a large number of countries, at different hierarchical levels, need to reach consensus. Due to this, and to the large number of chemicals to be tested within REACH, it is not realistic to expect that future standard test batteries will include a wide range of additional test methods and animal groups, which could be one way to improve the chemical control process (see e.g. Breitholtz et al. 2006a, 2006b).

Instead, to increase ecological realism and understanding in future regulatory work, we believe that alternative approaches can improve integration of ecology with baseline data from currently used standard test methods without much extra labor or cost. Since most ecotoxicological test methods are normally performed under optimal testing conditions (e.g. related to food quality/quantity, salinity, oxygen, $\mathrm{pH}, \mathrm{DOC}$, temperature, etc.), which may not be applicable for predicting toxic effects in ecosystems, in Section 2 we point to some suboptimal testing conditions that may be considered in regulating chemical substances. In Section 3 we present selected population modeling tools, which can use standard test endpoints, such as mortality and reproduction, to extrapolate to likely impacts at the population - or even the community level. In Section 4 we provide some suggestions on improvements of REACH and summarize our ideas.

\section{Suboptimal Testing Conditions}

\subsection{Background}

An ecotoxicological test is performed with the goal of investigating the impact of a chemical substance on ecological systems. The endpoints of such tests vary widely but are always based on stress-induced responses. Sibly 
and Calow (1989) have defined stress as an "environmental condition that reduces Darwinian fitness when first applied." Such environmental conditions typically occur when organisms are exposed to pollutants (e.g. metals and organic chemicals) or UV radiation, food quality/quantity is low, and/or tolerance limits related to e.g. temperature, salinity, oxygen saturation, hardness, and $\mathrm{pH}$ are exceeded. Although most organisms have an ability to regulate e.g. internal toxicant concentrations by detoxification and/or storage in the body, such activities cost energy, which means that less energy is available for other crucial processes in the body. This in turn means that organisms living under optimal conditions may better be able to handle stressors, such as chemicals, than organisms living under suboptimal conditions (e.g. Heugens et al. 2001, van der Geest et al. 2002).

In order to clearly quantify toxic effects of a chemical, current standard toxicity testing is normally performed in such a way that the organisms are exposed to a chemical under otherwise constant and optimal conditions. However, environmental conditions differ widely between different parts of the world, and even within ecosystems, which could mean that native organisms, as compared to the organisms used in the laboratory tests, are either more tolerant because they have adapted to handling external stressors, or less tolerant, as a result of combined chemical and environmental stress. Standard tests available within the large international standardization bodies, such as OECD and ISO, naturally cover only a minimal fraction of ecosystem diversity; freshwater species are, e.g. used to protect the marine environment, (high) temperatures provided by guidelines are often only representative for tropical regions, single species are used as representatives for tens of thousands or even millions of other species, etc. We can only speculate as to what extent this lack of ecological coverage limits the reliability of current chemicals regulation, but there is reason to believe that it is of major significance since so many unique biological and ecological systems and functions are missing.

In the following we will highlight a number of relevant environmental factors, which either alone or in combination may alter uptake and toxicity of both organic and inorganic chemicals, and which we think may be important for consideration in future chemicals regulation. We do not imply that the list of factors is complete, or that all of these factors should be considered as equally important for any given situation. Instead, our aim is to highlight some weak points in the current European chemicals legislation, which in some way need to be considered if the ecological relevance of $\mathrm{REACH}$ is to be improved. We are however fully aware that the selection of which environmental factors should be considered in REACH is a challenging task, which will need substantial research efforts in the future. We are also aware that changing environmental factors may have other implications (e.g. changes in community sensitivity due to lowered species diversity) than altered uptake and toxicity of chemicals, which may be equally or more important for ecosystem stability and functionality. However, since our focus is on the use of standard toxicity test data, such indirect ecosystem effects fall outside the scope of this chapter. 


\subsection{Environmental Factors of Importance for Uptake and Effects}

In brackish environments with low salinities, such as the Baltic Sea, only a few species are able to persist, and those that do, live close to their tolerance limits (Bonsdorff and Pearson 1999). Given that the Baltic Sea receives discharges from about 85 million people living in 14 countries in the Baltic Sea drainage basin (Hannerz and Destouni 2006), it could, from a European perspective, be important to consider combinations of e.g. stressful salinity conditions and the toxic effects of environmental pollutants. This is further highlighted by the fact that the effect of salinity may not only affect organisms directly, but may also interact with, and thus modify, the toxic compound (Heugens et al. 2001). For example, due to metal complexation, bioavailability of metals often decreases with increasing salinity, which leads to decreased toxicity (e.g. Chapman et al. 1998, Witters 1998, McGeer et al. 2002). Also in marine coastal areas, there is a risk of organisms being exposed to anthropogenic exposure and salinity fluctuations simultaneously (Forbes 1991, Heugens et al. 2001). Forbes (1991) for instance found that the gastropod Hydrobia ventrosa grew more rapidly at $23 \%$ compared to at $33 \%$, whereas at $13 \%$ o the gastropods did not grow at all. Interestingly, the negative effects of cadmium on growth were greatest at the highest salinity, and at the lowest salinity any effects of cadmium were masked by the salinity effect. Menezes et al. (2006), found lower levels of lactate dehydrogenase in brown shrimp (Crangon crangon L.) when they were exposed to simulated diurnal salinity conditions, and they concluded that this was due to energy loss associated with an increased osmotic burden.

Also temperature may influence the action of a toxicant, either by altering metabolism/detoxification (e.g. inducing heat shock or cold hardiness proteins), thus changing sensitivity towards a toxicant, or by changing feeding activity and thereby toxicant uptake (Heugens et al. 2001). In temperate coastal systems, temperature may fluctuate by $20^{\circ} \mathrm{C}$ annually (Camus et al. 2004), which could make standardized tests performed at one specific temperature of somewhat limited usefulness. Heugens et al. (2003) have for instance shown that, in D. magna, acute toxicity of cadmium differed substantially between $10^{\circ} \mathrm{C}$ and $35^{\circ} \mathrm{C}$, with higher toxicity at higher temperatures. Water temperature is additionally an important factor for oxygen saturation, which may also affect the physiological status of aquatic organisms. For instance, in a laboratory test, Gardeström et al. (2007) exposed dog whelks (Nucella lapillus) collected from the intertidal zone and exposed them to $16^{\circ} \mathrm{C}$ (ambient), $26.5^{\circ} \mathrm{C}$, and $30^{\circ} \mathrm{C}$ under normal and hyperoxic conditions, respectively. They did not observe any thermally induced mortality at $26.5^{\circ} \mathrm{C}$, but the mortality rate was $40-50 \%$ at $30^{\circ} \mathrm{C}$, which however was reduced to $10 \%$ if extra oxygen was provided. It seems as if the oxygen supply was setting the limit for the whole organisms' thermal tolerance.

In the study, tissue samples were also analyzed for protein-related parameters clearly showing that the stress response of dog whelks exposed to increased water temperatures differed from those exposed to lower temperatures, but that increased oxygen availability alleviated these differences thus increasing the simi- 
larity between heat-shocked and control animal protein patterns. This implies a more stable protein metabolism and might explain the increased survival of heatshocked individuals when extra oxygen is supplied. This in turn demonstrates the importance of adequate oxygen levels for handling stress, which is something that could be considered when performing standardized toxicity tests. Oxygenation is also important for redox conditions and hence for bioavailability of metals in sediments. In anoxic conditions an important partitioning phase for cationic metals is the formation of metal sulfides, which have low solubility and hence bioavailability (Di Toro et al. 1991). In oxic conditions many metals (e.g. Cd, Zn and $\mathrm{Cu}$ ) are instead associated to organic matter and inorganic structures, such as oxides, hydroxides of e.g. iron and manganese and clay minerals (Turner et al. 2004). Airas et al. (2008) have also shown that a combination of low dissolved oxygen concentrations and polluted sediment (but not low oxygen levels alone) reduced biomass in an oligochaete (Lumbriculus variegatus) and increased mortality in an insect (Chironomus riparius). From this study, the authors concluded that standard sediment toxicity tests may not provide sufficient data for risk assessment of contaminated sediments at sites where the actual conditions differ largely from laboratory conditions.

It is well-known that $\mathrm{pH}$ is of importance for bioavailability and uptake of many chemicals, such as metals (e.g. Chapman et al. 1998), but $\mathrm{pH}$ may also be important for the same processes concerning organic substances. Nakamura et al. (2008) recently showed that acute toxicity and bioconcentration of the pharmaceutical fluoxetine was affected by $\mathrm{pH}$ in the Japanese medaka (Oryzias latipes). Toxicity increased with increasing $\mathrm{pH}$ and bioconcentration was lower at $\mathrm{pH} 7$ and higher at $\mathrm{pH}$ 9, likely because of increase in nonionized forms with significantly higher hydrophobicity than the ionized forms at $\mathrm{pH}$ values closer to $\mathrm{pKa}$.

Organic material (e.g. food, particles) may influence bioavailability and bioaccumulation of both metals and hydrophobic organic substances, either by reducing or increasing uptake (e.g. Fliedner 1997, McGeer et al. 2002, De Schamphelaere et al. 2004, Wilding and Maltby 2006, Thorsson et al. 2008). Klüttgen and Ratte (1994) found that the development of juvenile D. magna was inhibited by cadmium at low food concentrations, while a body length reduction was clear at higher doses of food. The brood size was inhibited by $69 \%$ at high food levels, whereas no effect was found at low food levels at the same cadmium concentrations. Other studies have found effects on food availability and metal toxicity. For example, in acute toxicity tests, Chandini (1988) found that the cladocerans $D$. carinata and Echinisca triserialis were more sensitive to cadmium as food levels decreased, and Koivisto et al. (1992) found that in five cladoceran species (D. magna, D. pulex, D. galeata, Bosmina longirostris, and Chydorus sphaericus), copper exposure at low food levels decreased survival compared to high food levels. Further, although a sufficient amount of food may be available, it may still be of too low quality, which may have a negative impact on growth and reproduction (Li et al. 2008, Dahl et al. 2009). The choice of food may thus be of significant importance for risk characterizations based on standard toxicity tests, especially when using reproduction or population growth data since test organisms used to derive such chronic data need to be fed during testing. 
Not only may food availability during testing influence how organisms respond to toxicants, but feeding conditions used to maintain animal cultures may also influence test results. For example, Pieters and Liess (2006) have shown that maternal nutritional state may have a significant influence on offspring sensitivity to pollutants. In their study D. magna offspring from females raised under either low or high food conditions responded differently when exposed to the pesticide fenvalerate. Low maternal food conditions increased the offspring size at time of birth, reduced age at first reproduction and increased reproductive output, which jointly enhanced offspring fitness as estimated by the population growth rate $(\mathrm{r})$. Results also showed that fenvalerate exposure in combination with low maternal food levels caused a strong decrease in acute sensitivity of young daphnids (neonates), which was generally also observed for chronic endpoints.

Although it might seem logical to expect that animals with a high energy status are more successful in dealing with stress than animals with a low energy status, this may not be the case. Smolders et al. (2005) exposed D. magna to different food concentrations and measured energy status and scope for growth in animals exposed to a stressor (in this case increased salinities). Exposure to higher salinity significantly decreased survival and reproduction, but interestingly this decrease was more pronounced in the highest food concentrations, which shows that the high energy status of the daphnids from the high food concentrations at the start of the exposure did not provide an increased capacity to cope with additional stress. The authors speculated that this increased sensitivity was the result of a change in life history from emphasizing survival at low food supply to emphasizing reproduction at high food supply. The studies by Pieters and Liess (2006) and Smolders et al. (2005) clearly show that different testing conditions may have a profound impact on the outcome of standard toxicity testing and that this outcome may not be consistent with generally accepted hypotheses.

\section{Population Modeling}

\subsection{Available Tools}

Since the early 1990s, mathematical modeling has been accepted as a useful tool for developing exposure scenarios in environmental risk assessment, but has not received the same attention for effect characterization, although several techniques are available. Forbes et al. (2008) have identified three main classes of population models; i.e. demographic models, energy budget models, and individual based models. Demographic models describe individuals with regard to their survival and contribution to future generations (i.e. offspring) and can either be structured or unstructured. Structured models define individuals in certain classes based on age or size, whereas unstructured models treat all individuals within the population as identical. These general models can further be supplemented with stochastic events (demographic or environmental), and by adding spatial structure, meta-population models may be obtained. It is also pos- 
sible to incorporate density dependence, but this can in certain model formulations be difficult (Forbes et al. 2008). Energy budget models do not include survival as a response; instead, these models handle intake and output of energy for individuals, relating it to growth rate and reproduction. Individual based models consider each individual in a population and describe the individual responses. Population level patterns emerge from the combined responses of the individuals of which the population is composed. Individual based models are most powerful when they include great detail about individual exposures and responses and when they incorporate spatially and temporally realistic habitat features.

Population models can be used in environmental risk assessment for different purposes. They can "detect" (or diagnose the cause of) adverse effects on populations exposed to chemicals. Data on the population is used to detect changes in population attributes and relate them to disturbances. They can also "project"' the likely consequences on populations under a set of environmental conditions, such as exposure to chemicals (or other stressors), and provide decision-makers with information about how populations are doing (see also discussion on suboptimal testing conditions in Section 2). Lastly, population models can "forecast" the future behavior of populations which is based on understanding the environmental variability as well as the dynamic interactions of density and biological processes (Munns et al. 2007). The difference between projection and forecasting is that the projection is what would happen to the population (given certain hypothesis, e.g. different management decisions), and a forecast is something that will happen and is based on a deeper understanding and more data than a projection (Caswell 2001).

\subsection{Standard Test Data To Be Used for Regulatory Modeling}

In $\mathrm{REACH}$, for chemicals produced up to $100 \mathrm{t}$, it is not possible to use population modeling as an effect characterization tool since the standard tests required do not measure reproduction. However, for chemicals produced between 100 and 1,000 t, a chronic test with Daphnia is required, and for chemicals produced over 1,000 t reproduction tests with earthworms and chironomids are mandatory. For substances produced between 100 and 1,000 t, chronic tests with fish are also required, but there is currently no true reproduction test available with OECD or any other large international standardization body (however, a two-generation test is under development within OECD; see Table 1), which means that it will not be possible to generate adequate population data for fish under current testing requirements.

Further, since the reproduction test with Daphnia only comprises asexual reproduction, this also means that investigations focusing on sexual reproduction will be lacking for substances produced up to 1,000 t per producer and year. For substances produced above this production volume, the reproduction tests using earthworms and chironomids may however be used to generate adequate population data (see Table 1 for OECD test guidelines concerned with reproduction available for risk assessment in REACH. The proposals on copepods and fish are 
Table 1. Endpoints obtained from adopted and proposed OECD Test Guidelines suggested for use in REACH

\begin{tabular}{|c|c|}
\hline \multirow{2}{*}{$\begin{array}{l}\text { Daphnia reproduction (OECD guideline 211) } \\
\text { Mortality }\end{array}$} & Earthworm reproduction (OECD 2 \\
\hline & Mortality \\
\hline Offspring & Changes in behavior \\
\hline Length/volume of individuals & Fecundity (number of juveniles prc \\
\hline Time to production of first brood & Body mass \\
\hline Number and size of broods per animal & Pathological symptoms \\
\hline Number of aborted broods & \\
\hline Presence of males and ephippia & \\
\hline Chironomid toxicity (OECD 219) & $\begin{array}{l}\text { Fish reproduction, } 2 \text {-generation } \\
(\text { OECD proposal) })^{b}\end{array}$ \\
\hline Mortality & Survival \\
\hline Offspring production & Behavior \\
\hline Sex & Fecundity \\
\hline Weight of individuals & Fertilization success \\
\hline Mean development rate of emerged midges & $\begin{array}{l}\text { Hatchability, larvae appearance } \\
\text { and survival }\end{array}$ \\
\hline $\begin{array}{l}\text { Harpacticoid copepod development and } \\
\text { reproduction (OECD proposal) }\end{array}$ & $\begin{array}{l}\text { Appearance of adults } \\
\text { Gonad size and morphology, and }\end{array}$ \\
\hline $\begin{array}{l}\text { Mean development rates from nauplius to the } \\
\text { copepodite and adult stages, respectively }\end{array}$ & $\begin{array}{l}\text { biochemical- end points } \\
\text { (VTG, steroids) }\end{array}$ \\
\hline Fertilization success & \\
\hline Total viable offspring production per mating pair & \\
\hline Time to production of first clutch & \\
\hline Time interval between successive clutches & \\
\hline Aborted egg sacs & \\
\hline Necrotic and infertile eggs & \\
\hline Sex ratio & \\
\hline Stage specific mortalities & \\
\hline Abnormal behavior & \\
\hline
\end{tabular}

a. OECD (Organization for Economic Cooperation and Development). OECD Draft Guidelines for Testing of Chemicals. Proposal for a New Guideline. Harpacticoid Copepod Development and Reproduction Test, Paris, France (Version: 19th of February 2008 - Current version includes only the species Amphiascus tenuiremis).

b. OECD (Organization for Economic Cooperation and Development). Draft proposal for a new guideline. Fish Two-generation Test Guideline, Paris, France (Version: 8th of November 2002).

not yet adopted as OECD test guidelines but here serve as relevant examples). In all, this indicates that population modeling can only be part of the testing required for a rather small set of substances in the current system.

Table 2 is modified from Menzie et al. (2007) and contains attributes of organisms that can be used to obtain attributes of populations used in population modeling. The table highlights which of these attributes that can be derived from standard tests recommended in REACH and presented in Table 1. In our view, this clearly illustrates that population models may easily be incorporated into the regular risk assessment procedures within Europe. 
Table 2. Attributes that can be used in population modeling. The table is modified from Menzie et al. (2007). An asterisk $\left(^{*}\right)$ denotes endpoints that can be derived from OECD guidelines and proposals suggested for use in REACH

\begin{tabular}{|c|c|}
\hline \multicolumn{2}{|c|}{ Attributes of organisms } \\
\hline Demographics of individuals & Physiological characteristics \\
\hline Mortality* & Individual growth rate* \\
\hline $\begin{array}{l}\text { Reproductive state and output (e.g. fecundity, } \\
\text { births per female)* }\end{array}$ & $\begin{array}{l}\text { Respiration rate } \\
\text { Ingestion rate }\end{array}$ \\
\hline $\begin{array}{l}\text { Development rate (e.g. time for larval } \\
\text { development, time to maturity)* }\end{array}$ & Metabolism and excretion \\
\hline Age $^{*}$ & Genetic characteristics \\
\hline Size* & Individual genotypes \\
\hline Sex* & $\begin{array}{l}\text { Presence of particular alleles } \\
\text { Heterozygosity }\end{array}$ \\
\hline Ecology, behavior and exposure & \\
\hline Life history for individual* ${ }^{*}$ & Organism condition \\
\hline $\begin{array}{l}\text { Habitat and food preference or } \\
\text { location in space }\end{array}$ & $\begin{array}{l}\text { Condition factors (weight and length } \\
\text { relationships)* }\end{array}$ \\
\hline Locomotion, dispersal, migration and & Morbidity* \\
\hline spatial extent of an individual & Deformities* \\
\hline Individual environmental exposure & Tumors and other histopathological anomalies* \\
\hline \multicolumn{2}{|c|}{ Attributes of populations } \\
\hline Abundance & Population growth rate \\
\hline Population size* & Intrinsic rate of natural increase ${ }^{*}$ \\
\hline Population density* & Finite rate of population increase \\
\hline Equilibrium abundance (steady-state) & Birth, death, immigration and emigration rates \\
\hline \multicolumn{2}{|l|}{ Carrying capacity } \\
\hline Age class distribution* & Spatial distribution and habitat \\
\hline Size class distribution* & Spatial distribution across available habitat \\
\hline \multirow[t]{2}{*}{ Sex ratios* } & Critical patch size \\
\hline & Habitat requirements \\
\hline \multicolumn{2}{|l|}{ Genetic structure and variation } \\
\hline \multicolumn{2}{|l|}{ Genotypic frequencies } \\
\hline \multicolumn{2}{|l|}{ Heterozygosity } \\
\hline Genetic diversity & \\
\hline
\end{tabular}

\section{Suggestions for Improvements of REACH}

In the current chapter we have illustrated how varying physical environmental factors may have a profound impact on physiological and toxicological responses in a number of aquatic organisms. The influence of varying environmental factors may become even more important as a result of expected climate change, resulting in rapid alterations of biotic and abiotic factors, and thus these issues should be of concern for chemicals regulation (Schiedek et al. 2007). In this 
context, it is certainly welcomed that the European Union has adopted the new chemicals regulation REACH with its very ambitious aim to protect the environment. We are however concerned that REACH may fall short of its aim as long as it relies on relatively weak tools for hazard identification and dose-response assessment of chemicals. However, we believe that the European Union has the ability to improve the current regulation and testing guidelines.

Naturally, increased numbers of test animals, and financial costs for introducing a wide range of physical environmental conditions as an obligatory part of current standard guidelines, will severely limit the development and incorporation of additional standard tests. Hence, before suboptimal testing conditions can become a mandatory aspect of risk characterization procedures, it is crucial to identify which environmental factors are of major concern. Once key physical environmental factors have been established, it is further important to develop alternative approaches to minimize any extra costs (in terms of both economical values and animal welfare) associated with increased testing frequencies. In this context our proposed use of population models would help yield more relevant data in the sense that the models may be used to predict the outcome of varying physical environmental conditions on populations, communities or even ecosystems, without any further testing. Both demographic models that incorporate environmental stochastic events and individual-based models that incorporate spatially and temporally realistic habitat features may be useful in this context. In some cases more complex models may be needed, which needs to comprise assumptions and simplifications of biological and ecological interrelationships.

A suggestion for incorporating state-of-the-art knowledge (concerning e.g. behavior, tolerance, distribution pattern, etc.) in environmental risk assessment, which obviously is difficult to accomplish (see Section 1), would be to make use of such knowledge when constructing population models based on available baseline test data. We are aware that to e.g. add descriptive information or nonstandard scientific data may go against what is the general paradigm in risk assessment, but we strongly believe that such actions would not be more problematic than the simplifications of ecosystem functionality and the sometimes poor extrapolations between species used in current risk assessment guidelines. In our view, the mathematical models may instead strengthen potentially weak assumptions and increase the ecological realism of the standard testing.

Moreover, taking varying environmental factors into account in chemicals regulation doesn't necessarily mean that additional temperatures or oxygen levels must be tested over the full concentration range. Selected test chemical concentrations can be tested at NOEC and EC/LC50-values for preliminary betweentreatment comparisons. Further, when there are suspicions that there may be large regional differences in susceptibility to a certain chemical (possibly based on expert judgment) a new chemical ought to be tested at a range of physical environmental factors relevant for at least two of the most extreme regions within a certain area (e.g. Europe). For instance, Scandinavian freshwater systems are often oligotrophic, weakly buffered and threatened by low $\mathrm{pH}$, which means that they in many aspects differ significantly from freshwater systems of middle and Southern Europe. This in turn may, as described above, affect bioavailability and toxicity of many environmental pollutants, especially metals. 
In this context it is important to improve the analysis of the extent to which sensitive organisms and ecosystems in such areas may need specific test methods and specific concern in environmental risk assessment of chemicals (Breitholtz et al. 2006a). In the future, it is therefore important to increase research efforts to elucidate potential consequences of varying physical and chemical environmental factors for toxicity of a wide range of chemical substances, in order to develop tools for hazard identification and dose-response assessment that include scientifically well-based combinations of species, endpoints and environmental factors. The battery of endpoints to select from should, as far as possible, comprise population level data (Forbes and Calow 1999, Forbes et al. 2001, Breitholtz et al. 2006a), possibly obtained by using population models.

\section{Concluding Remarks}

In this chapter we have pointed to some fundamental physical environmental factors that in our view are important to take into account in order to improve REACH (and likely other chemical legislations). We have also pointed to the potential of an increased use of mathematical population models to obtain more relevant data for environmental risk assessment. With increased knowledge about how various physical environmental factors (e.g. temperature, $\mathrm{pH}$, salinity, $\mathrm{O}_{2}$ ) on one hand influence toxicity and on the other may be taken into account in the process of environmental risk assessment, chances will improve to achieve a process that is efficient, cost effective, scientifically robust, and meets the demands of science-based precaution. Environmental risk assessment within REACH would thus become a more diverse but at the same time more adequate process than the one presented in the current version.

\section{References}

Airas S., Leppanen M., Kukkonen J.V.K. (2008) Effects of temperature and oxygen concentration in sediment toxicity testing. Ecotoxicology and Environmental Safety 70(3): 475-482.

Bonsdorff E., Pearson T. H. (1999) Variation in the sublittoral macrozoobenthos of the Baltic Sea along environmental gradients: A functional-group approach. Australian Journal of Ecology 24: 312-326.

Breitholtz M., Rudén C., Hansson S. O., Bengtsson B-E. (2006a) Ten challenges for improved environmental risk assessment. Ecotoxicology and Environmental Safety 63: 324-335.

Breitholtz M., Eriksson J., Green N., Ruden C. (2006b) Testing and risk assessment of persistent and bioaccumulating chemical substances - Improvements within REACH? Human and Ecological Risk Assessment 12: 782-805.

Camus L., Davies P. E., Spicer J. I., Jones M. B. (2004) Temperature-dependent physiological response of Carcinus maenas exposed to copper. Marine Environmental Research 58: 781-785.

Caswell H. (2001) Matrix Population Models-Construction, Analysis and Interpretation. Sinauer Associates, Sunderlands, MA.

Chandini T. (1988) Changes in food (Clorella) levels and the acute toxicity of cadmium to Daphnia carinata (Daphnidae) and Echinisca triserialis (Microthricidae)[Crustacea, Cladocera]. Bulletin of Environmental Contamination and Toxicology 41(3): 398-403. 
Chapman P. M., Wang F. Y., Janssen C., Persoone G., Allen H. E. (1998) Ecotoxicology of metals in aquatic sediments: Binding and release, bioavailability, risk assessment, and remediation. Canadian Journal of Fisheries and Aquatic Sciences 55(10): 2221-2243.

Dahl U., Rubio-Lind C., Gorokhova E., Eklund B., Breitholtz M. (2009) Food quality effects on copepods in toxicity tests. Ecotoxicology and Environmental Safety 72(2): 351-357.

De Schamphelaere K., Vasconcelos F., Tack F., Allen H. E., Janssen C. (2004) Effect of dissolved organic matter source on acute copper toxicity to Daphnia magna. Environmental Toxicology and Chemistry 23(5): 1248-1255.

Di Toro D. M., Zabra C. S., Hansen D. J., Berry W. J., Swartz R. C., Cowan C. E., Pavlou S. P., Allen H. E., Thomas N. A., Paquin P. R. (1991) Technical basis for establishing sediment quality criteria for nonionic organic chemicals using equilibrium partitioning. Environmental Toxicology and Chemistry 10: 1541-1583.

European Commission (2003) Technical guidance document in support of commission directive 93/67/EEC on risk assessment for new notified substances and commission regulation (EC) No 1488/94 on risk assessment for exiting substances. Luxembourg, ISBN: 92-827-8011-2.

Fliedner A. (1997) Ecotoxicity of poorly water-soluble substances. Chemosphere 35(1/2): 295-305.

Fleeger J. W., Carman K. R., Roger Nisbet M. (2003) Indirect effects of contaminants in aquatic ecosystems. Science of the Total Environment 317: 207-233.

Forbes V. E. (1991) Response of Hydrobia ventrosa (Montagu) to environmental stress effects of salinity fluctuations and cadmium exposure on growth. Functional Ecology 5(5): 642-648.

Forbes V. E., Calow P. (1999) Is the per capita rate of increase a good measure of populationlevel effects in ecotoxicology? Environmental Toxicology and Chemistry 18(7): 1544-1556.

Forbes V. E., Calow P., Sibly R. M. (2001) Are current species extrapolation models a good basis for ecological risk assessment? Environmental Toxicology and Chemistry 20(2): 442-447.

Forbes V. E., Calow P., Sibly R. (2008) The extrapolation problem and how population modelling can help. Environmental Toxicology and Chemistry 27(10): 1987-1994.

Gardeström J., Elfwing T., Lof M., Tedengren M., Davenport J. L., Davenport J. (2007) The effect of thermal stress on protein composition in dogwhelks (Nucella lapillus) under non-normoxic and hyperoxic conditions. Comparative Biochemistry and Physiology A - Molecular and Integrative Physiology 148(4): 869-875.

Hannerz F., Destouni G. (2006) Spatial characterization of the Baltic Sea drainage basin and its unmonitored catchments. Ambio 35(5): 214-219.

Heugens E.H.W., Hendriks A. J., Dekker T., van Straalen N. M., Admiraal W. (2001) A review of the effects of multiple stressors on aquatic organisms and analysis of uncertainty factors for use in risk assessment. Critical Reviews in Toxicology 31(3): 247-284.

Heugens E.H.W., Jager T., Creyghton R., Kraak M.H.S., Hendriks A. J., Van Straalen N. M., Admiraal W. (2003) Temperature-dependent effects of cadmium on Daphnia magna: Accumulation versus sensitivity. Environmental Science and Technology 37(10): 2145-2151.

Klüttgen B., Ratte H. T. (1994) Effects of different food doses on cadmium toxicity to Daphnia magna. Environmental Toxicology and Chemistry 13(10): 1619-1627.

Koivisto S., Ketola M., Walls M. (1992) Comparison of 5 cladoceran species in short-term and long-term copper exposure. Hydrobiologia 248(2): 125-136.

Li J., Sun S., Li C., Zhang Z., Pu X. (2008) Effects of different diets on the reproduction and naupliar development of the copepod Acartia bifilosa. Journal of Experimental Marine Biology and Ecology 355(2): 95-102.

McGeer J., Szebedinszky C., McDonald G., Wood C. (2002) The role of dissolved organic carbon in moderating the bioavailability and toxicity of $\mathrm{Cu}$ to rainbow trout during chronic waterborne exposure. Comparative Biochemistry and Physiology Part C 133: 147-160.

Menezes S., Soares A.M.V.M., Guilhermino L., Peck M. R. (2006) Biomarker responses of the estuarine brown shrimp Crangon crangon L. to non-toxic stressors: temperature, salinity and handling stress effects. Journal of Experimental Marine Biology and Ecology 335(1): 114-122. 
Menzie C., Bettinger N., Fritz A., Kapustka L., Regan H., Moller V., Noel H. (2007) Population protection goals. In: Barhthouse L. W., Munns W. R. Jr., Sorensen M. T. (eds.) Population-level ecological risk assessment. CRC, Boca Raton.

Millennium Ecosystem Assessment Series (2005) Ecosystems and human well-being: Current state and trends. Findings of the condition and trends working group, chapter 15. ISBN: 1-55963-228-3.

Munns W., Gervais J., Hoffman A., Hommen U., Diane N., Nakamaru M., Sibly R., Topping C. (2007) Modelling approaches to population-level ecological risk assessment. In: Barhthouse L. W., Munns W. R. Jr., Sorensen M. T. (eds.) Population-level ecological risk assessment. CRC, Boca Raton

Nakamura Y., Yamamoto H., Sekizawa J., Kondo T., Hirai N., Tatarazako N. (2008) The effects of $\mathrm{pH}$ on fluoxetine in Japanese medaka (Oryzias latipes): Acute toxicity in fish larvae and bioaccumulation in juvenile fish. Chemosphere 70: 865-873.

Organization for Economic Cooperation and Development (1998) Daphnia magna reproduction test. OECD Guidelines for Testing of Chemicals. Technical Guidance Document 211.

Organization for Economic Cooperation and Development (2004a) OECD Guidelines for the Testing of Chemicals, Sediment-water chironomid toxicity test using spiked water, OECD 219, adopted 13 April 2004.

Organization for Economic Cooperation and Development (2004b) OECD Guideline for the Testing of Chemicals, Earthworm Reproduction Test (Eisenia fetida/Eisenia Andrei), OECD 222, adopted 13 April 2004.

Pieters B. J., Liess M. (2006) Maternal nutritional state determines the sensitivity of Daphnia magna offspring to short-term Fenvalerate exposure. Aquatic Toxicology 76: 268-277.

Rudén C., Hansson S. O. (2006) Improving REACH. Regulatory Toxicology and Pharmacology 44: 33-42.

Schiedek D., Sundelin B., Readman J. W., Macdonald R. W. (2007) Interactions between climate change and contaminants. Marine Pollution Bulletin 54: 1845-1856.

Sibly R., Calow P. (1989) A life-cycle theory of responses to stress. Biological Journal of Linnean Society 37(1-2): 101-116.

Smolders R., Baillieul M., Blust R. (2005) Relationship between the energy status of Daphnia magna and its sensitivity to environmental stress. Aquatic Toxicology 73: 155-170.

Swedish Chemicals Inspectorate (2007) REACH Factsheet. http://www.kemi.se/upload/ Trycksaker/Pdf/Faktablad/FbReachMars08.pdf

Thorsson M. H., Hedman J. E., Bradshaw C., Gunnarsson J. S., Gilek M. (2008) Effects of settling organic matter on the bioaccumulation of cadmium and BDE-99 by Baltic Sea benthic invertebrates. Marine Environmental Research 65(3): 264-281.

Turner, A., Millward G. E., Le Roux S. M. (2004) Significance of oxides and particulate organic material in controlling trace metal partitioning in a contaminated estuary. Marine Chemistry 88: 179-192.

van der Geest H. G., Soppe W. J., Greve G. D., Kroon A., Kraak M.H.S. (2002) Combined effects of lowered oxygen and toxicants (copper and diazinon) on the mayfly Ephoron virgo. Environmental Toxicology and Chemistry 21(2): 431-436.

Wilding J., Maltby L. (2006) Relative toxicological importance of aqueous and dietary metal exposure to a freshwater crustacean: Implications for risk assessment. Environmental Toxicology and Chemistry 25(7): 795-1801.

Witters H. E. (1998) Chemical speciation dynamics and toxicity assessment in aquatic systems. Ecotoxicology and Environmental Safety 41: 90-95. 